\title{
Incidence and Demographic Patterns of Orofacial Clefts in Mysuru, Karnataka, India: A Hospital-based Study
}

\author{
${ }^{1}$ Praveen Kumar PS, ${ }^{2}$ Kanika S Dhull, ${ }^{3}$ Lakshmikantha G, ${ }^{4}$ Nikita Singh
}

\begin{abstract}
Objective: The study was conducted to know the incidence and trends of orofacial clefts between 1st January 2011 and 31st August 2016 in Mysuru, Karnataka; and to describe the demographic patterns.
\end{abstract}

\begin{abstract}
Materials and methods: This is a retrospective, hospitalbased study. Data were retrieved from multiple sources like Parturition books, Neonatal intensive care unit records, baby and mothers case records archived in medical records department of Cheluvamba Hospital, a Tertiary Care Government Hospital, attached to Mysore Medical College and Research Institute, Mysore, Karnataka, between 1 January 2011 and 31 August 2016. All subjects with $C L \pm P$ were included in the study. Data were collected using semi-structured proforma, designed based on the review of the literature. Prior to the study, approval of the Institutional Ethics Committee was obtained. Collected data were subjected to descriptive statistical analysis using SPSS version 21 (SPSS Inc.).

Results: A total of 59 children with $\mathrm{CL} \pm \mathrm{P}$ were born between 1 January 2011 and 31 August 2016 among 77667 births (Male: 36,625; Females: 41042). Hence the incidence of orofacial clefts in this hospital was $0.76 / 1000$ births/year. Incidence in boys was $0.71 / 1000$ births and in girls it was $0.78 / 1000$ births $(p<0.7)$. Distribution of $C L \pm P$ showed that cleft lip with palate were more prevalent, which was $64.4 \% .54 .2 \%$ of the female child had clefts. Pierre-Robin syndrome was the most common associated malformation.
\end{abstract}

Conclusion: This study indicates that $C L \pm P$ are the most common types of orofacial clefts. Adequate ante-natal history in birth records is not been given critical importance, with lack of parental counseling. Public awareness regarding the early diagnosis of orofacial clefts, follow up, surgery and dental therapy is required.

Keywords: Cleft lip and palate, Congenital, Incidence, Syndrome.

\footnotetext{
${ }^{1}$ Associate Professor, ${ }^{2}$ Reader, ${ }^{3}$ Assistant Professor, ${ }^{4}$ Postgraduate Student

${ }^{1}$ Department of Dentistry, Mysore Medical College and Research Institute, Mysuru, Karnataka, India

${ }^{2}$ Department of Pedodontics and Preventive Dentistry, Kalinga Institute of Dental Sciences, KIIT University, Odisha, India

${ }^{3.4}$ Department of Obstetrics and Gynaecology, Mysore Medical College and Research Institute, Mysuru, Karnataka, India
}

Corresponding Author: Praveen Kumar PS, Associate Professor, Department of Dentistry, Mysuru Medical College and Research Institute, Mysuru, Karnataka, India, Phone: 9986817317, e-mail: docprav@gmail.com
How to cite this article: Kumar PSP, Dhull KS, Lakshmikantha G, Singh N, Incidence and Demographic Patterns of Orofacial Clefts in Mysuru, Karnataka, India: A Hospital-based Study. Int J Clin Pediatr Dent, 2018;11(5):371-374.

Source of support: The study was funded by the Ministry of Health, Riyadh, Kingdom of Saudi Arabia.

Conflict of interest: None

\section{INTRODUCTION}

Cleft lip with or without palate $(C L \pm P)$ is the most frequently occurring congenital malformations of the head and neck among live births, accounting for $65 \%$ of all head and neck anomalies. These clefts occur when the lip or palate fail to fuse during their prenatal development (first trimester). ${ }^{1}$ Although hereditary, Cleft Lip-Palate is believed to be multifactorial rather than a single-gene disease with various etiologies like chemical exposures, radiation, maternal hypoxia, teratogenic drugs, nutritional deficiencies, etc., playing a role. ${ }^{2}$ Patients affected with orocial clefts present complex biologic, sociologic and psychologic problems and rehabilitation requires a multidisciplinary approach. The functional outcome depends on the timing of surgery, type of repair, physiotherapy and proper follow-up. Studies have shown that the incidence and prevalence of Cleft lip-palate are 1 in 600 (1:600) and 9.92 per 10,000 worldwide respectively. The Cleft lip and cleft lip-palate prevalence are 3.28 per 10,000 , and 6.64 per $10,000 .{ }^{3}$ Cleft lip and palate is more frequently observed in males than females, but the prevalence varies with geographic locations, races, and ethnic groups. Cleft lip-palate can be unilateral or bilateral, may occur as both cleft lip and palate or either on its own. In case of pre alveolar clefts, unilateral clefts $(75 \%)$ are more frequent than the bilateral clefts $(25 \%)$. Fifty percent of deformities are combined clefts of the lip and palate. About $25 \%$ are bilateral ones. Approximately $30 \%$ of cleft lip-palate cases are observed to be associated with a syndrome and are presented with some other anomalies that behave differently epidemiologically from clefts without associated malformations. ${ }^{4,5}$

Various epidemiological studies conducted worldwide have shown a wide disparity in the risk of developing clefts within races and incidence. Hence this study was conducted to know the incidence and trends of 
orofacial clefts between 1st January 2011 and 31st August 2016 in Mysore, South India; and to describe the demographic patterns.

\section{MATERIALS AND METHODS}

This is a retrospective, hospital-based study. The data was retrieved from multiple sources like Parturition books, neonatal intensive care unit (NICU) records, baby and mothers case records archived in Medical Records Department of Cheluvamba Hospital, attached to Mysore Medical College and Research Institute, Mysore, Karnataka, between 1 January 2011 and 31 August 2016. All subjects with CL \pm P were included in the study. This hospital is a Tertiary Health Care Center run by the government, for women and child with approximately 1300 deliveries done every month, one of the highest in the state. It receives patients from all over Mysore district, including from surrounding districts of south Karnataka and different strata of society. The characteristics of this hospital made it appropriate for conducting this study. The data was collected using semi-structured proforma, designed based on the review of the literature. Prior to the study, approval of the Institutional Ethics Committee was obtained

Collected data were subjected to descriptive statistical analysis using SPSS version 21 (SPSS Inc.). The cleft samples were compared for variables such as types of the cleft, syndrome or non-syndrome, treatment provided, gender, mother's age, parity, consanguinity, infant's weight, term. Then, the factors mentioned above were analyzed with Chi-square test.

\section{RESULTS}

A total of 59 children with $\mathrm{CL} \pm \mathrm{P}$ were born between 1 January 2011 and 31 August 2016 among 77667 births (Male: 36,625; Females: 41042). Hence the incidence of orofacial clefts in this hospital was $0.76 / 1000$ births / year. Incidence in boys was $0.71 / 1000$ births and in girls it was
$0.78 / 1000$ births $(p<0.7)$. Distribution of $C L \pm P($ Table 1$)$ shows that cleft lip with palate is more prevalent, which was $64.4 \%$. Least was cleft palate only with $11.9 \% .54 .2 \%$ of the female child had clefts, and male child with clefts was $45.8 \%$ (Table 2 ).

A total of $91.5 \%$ of children with clefts were born of mothers, whose age was less than 30 years. $81.4 \%$ of births were of 1 or 2 mother's parity. $59.3 \%$ of children's weight at birth was below 2500 gms. 33.9\% were born of the consanguineous marriage. $13.9 \%$ of clefts were associated with various syndromes. No treatment was done in the hospital and were referred to other centers, with suitable facilities (Table 3). Pierre-Robin Syndrome was the most common associated malformation (Table 4).

\section{DISCUSSION}

This study was conducted in a tertiary health care hospital in the urban area which receives a large rural population in and around Mysore, and not presenting any significant variation.

There are more than 10 million people having clefts of lip and palate worldwide. The reported incidence is 0.8-1. ${ }^{6}$ for every 1000 births. 6 The present study showed the incidence of orofacial clefts in this hospital to be 0.76 / 1000 births / year which is comparable to different studies conducted all over the world. The study conducted in Tehran by Jamilian et al. showed the incidence of CL \pm P infants as 2.14 per 1000 live births. ${ }^{7}$ The incidence of $\mathrm{CL}+\mathrm{P}$ was 1.81 per 1000 live births in $\mathrm{Korea}^{8}$ and 1.91 per 1000 live births in Pakistan. ${ }^{9}$ There is a greater incidence of palatal clefts, with figures of up to 1:300 live births among Native Americans. ${ }^{10}$ Owens et al. ${ }^{11}$ found the incidence rate of 1.4:1000 births in England. In Italy, Calzolari et al. ${ }^{12}$ found 1.3:1000 and 0.6-0.7:1000 live births in Sweden. ${ }^{13}$ In Ireland, the incidence was 1.28:1000. ${ }^{14}$ In Mangalore, India Supriya et al. found the incidence to be $2.42 / 1000$ births year. $^{15}$

Table 1: Distribution of cleft types

\begin{tabular}{llll}
\hline Type of cleft & Total & Percent (\%) & Prevalence in 1000 live births \\
\hline Cleft lip & 14 & 23.7 & 0.18 \\
Cleft lip + palate & 38 & 64.4 & 0.49 \\
Cleft palate & 07 & 11.9 & 0.09 \\
Total & 100 & 100 & 0.76 \\
\hline
\end{tabular}

Table 2: Distribution of cleft according to gender

\begin{tabular}{llll}
\hline Type of cleft & Girls & Boys & Total (Percent) \\
\hline Cleft lip & $04(6.8 \%)$ & $10(16.9 \%)$ & $14(23.7)$ \\
Cleft lip + palate & $22(37.2 \%)$ & $16(27.2 \%)$ & $38(64.4)$ \\
Cleft palate & $04(6.8 \%)$ & $03(5.1 \%)$ & $07(11.9)$ \\
Total & $30(50.9 \%)$ & $29(49.1 \%)$ & $59(100)$ \\
\hline
\end{tabular}


Table 3: Distribution of subjects according to related factors

\begin{tabular}{|c|c|}
\hline Related factors & Count (Percentage) \\
\hline \multicolumn{2}{|l|}{ Gender } \\
\hline Girl & $32(54.2)$ \\
\hline Boy & $27(45.8)$ \\
\hline \multicolumn{2}{|l|}{ Mother's age } \\
\hline Less than 30 years & $54(91.5)$ \\
\hline 30 and above & $05(8.5)$ \\
\hline \multicolumn{2}{|l|}{ Mother's Parity } \\
\hline 1 and 2 & $48(81.4)$ \\
\hline 3 and higher & $11(18.6)$ \\
\hline \multicolumn{2}{|c|}{ Consanguineous marriage } \\
\hline No & $39(66.1)$ \\
\hline Yes & $20(33.9)$ \\
\hline \multicolumn{2}{|l|}{ Infant's Weight } \\
\hline Above $2500 \mathrm{~g}$ & $24(40.7)$ \\
\hline Below $2500 \mathrm{~g}$ & $35(59.3)$ \\
\hline \multicolumn{2}{|l|}{ Term } \\
\hline Pre-term & $13(22)$ \\
\hline Term & $46(76)$ \\
\hline \multicolumn{2}{|l|}{ Syndrome } \\
\hline No & $51(86.4)$ \\
\hline Yes & $08(13.6)$ \\
\hline \multicolumn{2}{|l|}{ Treatment done } \\
\hline No & $59(100)$ \\
\hline Yes & $00(0)$ \\
\hline \multicolumn{2}{|l|}{ Religion } \\
\hline Hindu & $53(89.8)$ \\
\hline Muslim & $06(10.2)$ \\
\hline
\end{tabular}

In this study, $54.2 \%$ of the female child had clefts, and male child with clefts was $45.8 \%$, which is in contrast to worldwide sex distribution data (Female: Male $=60: 40){ }^{16,17}$ It was also noted that isolated cleft palate was more common in females. Similar findings were reported by Uppal et al., ${ }^{18}$ Ibrahim et al., ${ }^{19}$ Habib. ${ }^{20}$ Studies by Jamilian et al. and Iregbulem ${ }^{21}$ reported that both types of clefts were equally distributed between males and females. A study conducted by Murthy et al. ${ }^{22}$ showed sex distribution of oral clefts was more in males than females. Studies from Europe and the USA ${ }^{23,24}$ showed females were less often affected. A study conducted by Sah and Powar showed among all cleft cases, $55.7 \%$ were males, and $44.3 \%$ were females. ${ }^{25}$

Sixty-four percent of patients had combined cleft lip and palate, followed by $23.7 \%$ with cleft lip and $11.9 \%$ with cleft palate. Unilateral clefts are more common than bilateral cleft which were seen only in 5 patients $(8.5 \%)$. Similar results were shown in the studies conducted by Uppal et al. ${ }^{18}$ and Samuel et al. ${ }^{26}$
Table 4: Associated malformation

\begin{tabular}{|c|c|c|}
\hline & Count & Percentage \\
\hline Associated_Malformation & 16 & 27.1 \\
\hline Piere-Robin syndrome & 3 & 5.1 \\
\hline HELLP Syndrome & 1 & 1.7 \\
\hline $\begin{array}{l}\text { Dandy-Walker cyst, Meningocele, } \\
\text { Occipital Encephelocoele, multipal } \\
\text { neural defects }\end{array}$ & 1 & 1.7 \\
\hline $\begin{array}{l}\text { Hydrocele with spinabifide with } \\
\text { meningocele }\end{array}$ & 1 & 1.7 \\
\hline $\begin{array}{l}\text { Hypertelorism with depressed Nasal } \\
\text { Bridge }\end{array}$ & 1 & 1.7 \\
\hline $\begin{array}{l}\text { Dysplastic ears, bilateral renal } \\
\text { agenesis }\end{array}$ & 1 & 1.7 \\
\hline Birth Asphysia, H I E of New Born & 1 & 1.7 \\
\hline Post-natal poly dactaly & 1 & 1.7 \\
\hline Hypo spadiasis & 1 & 1.7 \\
\hline Anaemic & 1 & 1.7 \\
\hline Preauricular Tag's & 1 & 1.7 \\
\hline Broncho pneumonia & 1 & 1.7 \\
\hline Sirenomelia, DEAD & 1 & 1.7 \\
\hline Pneumonia, DEAD & 1 & 1.7 \\
\hline \multicolumn{3}{|l|}{$0.76 / 1000$ incidence overall } \\
\hline \multicolumn{3}{|l|}{$0.71 / 1000$ incidence in males } \\
\hline $0.79 / 1000$ incidence in females & & \\
\hline$p$ value $=0.7$, Chi-square test & & \\
\hline
\end{tabular}

In this study, all the patients belonged to the lower socio-economic status. The mother's age and parity were found not statistically significant in relation to the orofacial clefts. Habib ${ }^{20}$ stated that incidence of the clefts probably increases with mother's age.

In this study, the association between consanguinity and orofacial clefts was not statistically significant. But $33.9 \%$ of patients were born of the consanguineous marriage. Studies by Jamilian ${ }^{7}$ Sah, Powar ${ }^{25}$ Harville $^{27}$ have revealed that the risk of orofacial clefts increased in consanguineous marriage.

In this study, Infants weight of $59.3 \%$ of the patients with orofacial clefts was below 2500 gms (Ranging from 1200 gms-2400 gms), which was significant. Studies by Rintala and Gylling, ${ }^{28}$ Jamilian $^{7}$ have shown a relation between the lower average birth weight of infants and orofacial clefts. However, Hennrikson ${ }^{29}$ reported a mean birth weight of 3405.6 gms for children with clefts.

Due to lack of adequate information's from birth records and ante-natal history, all possible risk factors for every patient was unable to record and assess. If complete ante-natal history is recorded, accurate knowledge of the role of risk factors such as Consanguinity, familial occurrence, Low birth weight, Mothers age, and parity could be assessed. 


\section{CONCLUSION}

A total of 59 children with $C L \pm P$ were born between 1 January 2011 and 31 August 2016. The incidence of orofacial clefts was $0.76 / 1000$ births/year. Parental counseling was lacking, which necessitates the setting up of cleft clinics at government hospitals. People should be advised to avoid consanguineous marriage. The government should develop adequate infrastructure in the health sector for awareness, identification, and treatment of clefts. Adequate ante-natal history in the birth records need to be accurately recorded. Identification of the risk factors causing clefts is crucial for the prevention and treatment of orofacial clefts. Along with post-surgical care, psychological treatment in the form of parental counseling forms an important aspect of the treatment modality.

\section{ACKNOWLEDGMENT}

We acknowledge the Medical superintendent of Cheluvamba Hospital, Staff of Medical Records Section, friends in the Department of Dentistry, K R Hospital. We, Thank Dr Sumanth MM, Assistant Professor, Department of Community Medicine, Mysore Medical College for Statistical analysis.

\section{REFERENCES}

1. Redett RJ. A guide to understanding Cleft Lip and palate, Dallas,Texas: Children's craniofacial association 2009.

2. M M Tolarova, Cervenka J- classification and birth prevalence of orofacial clefts. American journal of medical genetics. 1998;75(2):126-137.

3. Schutte B.C., Murray J.C. "The many faces and factors of orofacial clefts," Hum Mol Genet. 1999;8(10):1853-1859.

4. Wang X. "Surgical correction of secondary deformities with lip and palate cleft.," Zhonghua Kou Qiang Yi Xue Za Zhi. 2004;39(5):362.

5. Dvivedi J, Dvivedi S. A clinical and demographic profile of the cleft lip and palate in Sub-Himalayan India: A hospitalbased study. Indian J Plast Surgery, 2012;45(1):115-120.

6. Wanjeri JK, Wachira JM. Cleft lip and palate: A descriptive comparative, retrospective, and prospective study of patients with cleft deformities managed at 2 hospitals in Kenya. J Craniofac Surg 2009;20(5):1352-1355.

7. Jamilian A, Nayeri F, Babayan A. Incidence of cleft lip and palate in Tehran. J Indian Soc Pedod Prev Dent. 2007;25(4): 174-176.

8. Kim S, Kim WJ, Oh C, Kim JC. Cleft lip and palate incidence among the live births in the Republic of Korea. J Korean Med Sci 2002;17(1):49-52.

9. Elahi MM, Jacson IT, Elahi O, Khan AH, Mubarak F, Tariq GB, et al. Epidemiology of cleft lip and palate in Pakistan. Plast Reconstr Surg 2004;113(6):1548-1555

10. Zieglowski V, Hemprich A. Facial cleft birth rate in former East Germany before and after the reactor accident in Chernobyl. Mund Kiefer Gerichtschir 1999;3(4):195-199
11. Owens JR, Jones JW, Harris F. Epidemiology of facial clefting. Arch Dis Child. 1985;60(6):521-524.

12. Calzolari E, Milan M, Carazzuti GB, Cocchi G, Gandini E, Magnani C, et al. Epidemiological and genetics study of 200 cases of oral cleft in the Emilia Romagna region of northern Italy. Teratology 1988;38:559-566.

13. Hagberg C, Larson O, Milerad J. Incidence of cleft lip and palate and risks of additional malformations. Cleft Palate Craniofac J 1998;35:40-45.

14. Gregg T, Boyd D, Richardson A. The incidence of cleft lip and palate in Northern Ireland from 1980-1990. Br J Orthod 1994; 21:387-392.

15. Nambiar S, Singhal P, Menon A, Unikrishnan B. Clinicoepidemiological profile of orofacial clefts among children of coastal district of Southern India: A 5 year hospital based study. J Cleft Lip Palate Craniofac Anomal , 2014; 1(1): 34 -37.

16. Manyama M, Rolian C, Gilyoma J, Magori CC, Mjema K, Mazyala E, et al. An assessment of orofacial clefts in Tanzania. BMC Oral Health 2011;1:5.

17. Rakotoarison RA, Rakotoarivony AE, Rabesandratana N, Razafindrabe JB, Andriambololona R, Andriambololo-Nivo $\mathrm{R}$, et al. Cleft lip and palate in Madagascar 1998-2007. Br J Oral Maxillofac Surg 2012;50:430-434.

18. Uppal SK, Shah S, Mittal RK, Garg R, Gupta A. Epidemiology and clinical profile of cleft lip and palate patients, in a tertiary institute in Punjab, India: A preliminary study. J Cleft Lip Palate Craniofac Anomal 2016;3:32-35.

19. Ibrahim A, Mshelbwala PM, Obiadazie AC, Ononiwu CN, Asuku ME, Ajike SO, et al. A descriptive study of clefts of the primary and secondary palate seen in a tertiary institution in Nigeria. Niger J Surg Res 2015;15:12.

20. Habib Z. Factors determining occurrence of cleft lip and cleft palate. Surg Gynecol Obstet 1978;146:105-110.

21. Iregbulem LM. The incidence of cleft lip and palate in Nigeria. Cleft Palate J 1982;19:201-205.

22. Murthy J, Babu GV, Bhaskar LVKS. Clinical and demographic factors associated with cleft lip and palate in south india: a hospital based study. International Journal of Latest Research in Science and Technology. 2014;3(3):80-83.

23. Hagberg C, Larson O, Milerad J. Incidence of cleft lip and palate and risks of additional malformations. Cleft Palate Craniofac J 1998;35:40-45.

24. Gregg T, Boyd D, Richardson A. The incidence of cleft lip and palate in Northern Ireland from 1980-1990. Br J Orthod 1994; 21:387-392

25. Sah RK, Powar R. Epidemiological Profile of Cleft Lip and Palate Patients Attending Tertiary Care Hospital and Medical Research Centre, Belgaum, Karnataka-A Hospital Based Study. IOSR Journal of Dental and Medical Sciences IOSRJDMS. 2014;13(5):78-81.

26. Samuel S, Prasad RB, Kumari S, Tejaswi SS, Sanal TS. A clinical study of incidence and distribution and co- relating factors of cleft lip and cleft palate among karnataka \& kerala population. Nitte University of Health Sciences, 2014;4(3):66-69.

27. Harville EW, Wilcox AG, Lie RT, Vindenes H, Abyholm F. Cleft lip and palate versus cleft lip only: Are they distinct defects? Am J Epidemiol 2005;162:448-453.

28. Rintala AE, Gylling U. Birth weight of infants with cleft lip and palate. Scand L Plast Reconstr Surg 1967;1:109-112.

29. Hennrikson TG. Cleft lip and palate in Sweden: A genetic and clinical investigation. The institute for medical genetics of the university of Uppsala: Thesis; 1971. 